\title{
Types of Facets on the Superior Articular Surface of Isan-Thai Dried Calcanei
}

\author{
Tipos de Facetas de la Superficie Articular Superior \\ de Calcáneos Secos de Tailandeses del Nordeste
}

Sitthichai Iamsaard"; Nongnut Uabundit*; Porntip Boonruangsri*; Tarinee Sawatpanich* \& Wiphawi Hipkaeo*

IAMSAARD, S.; UABUNDIT, N.; BOONRUANGSRI, P.; SAWATPANICH, T. \& HIPKAEO, W. Types of facets on the superior articular surface of Isan-Thai dried calcanei. Int. J. Morphol., 33(4):1549-1552, 2015.

SUMMARY: The patterns of talar articulating facets must be concerned in surgical procedure or the internal and external fixation in various diseases of the foot. The variant types of calcaneal facets on the superior articular surface have been reported in many races except in Thais. This study therefore was aimed to investigate the patterns of superior articulating facet of dried calcanei in Isan-Thais. The identified 396 Isan- Thai dried calcanei (202 males and 194 females) were carried out for variant superior facet observations. The results showed that types of facets observed could be classified into three major types (Type 1 [60.86\%], Type 2 [38.64\%], and Type 4 [0.51\%], respectively). In sub-type classifications, there were Type 1A (24.75\%), Type 1B (36.11\%), Type 2A (12.88\%), Type 2B (14.14\%), Type 2C (2.78\%), Type 2D $(8.84 \%)$, and Type $4(0.51 \%)$, respectively. Additionally, it was found that the percentage of Type $2 \mathrm{~A}$ of male $(15.84 \%)$ was much greater than that of female (9.79\%) compared to those of other types. This incidence of facet types is valuable information for Thai orthologists to concern about treating in talocalcaneal joint area.

KEY WORDS: Types; Talar articulating facets; Isan-Thai calcanei.

\section{INTRODUCTION}

Anatomically, the facets of superior articular surface (anterior, middle, and posterior) of calcanei articulate with the head of overlying talus to form a subtalar joint which is called "the talocalcaneal joint". This joint is functionally important for foot movements such as inversion and eversion positions. In addition, such talar articulating facets associated with sustentaculum tali facet of calcaneal bone are involved in major stability of subtalar joint (Drayer-Verhagen, 1993). Morphologically, the variant types and incidence of facets on the superior articular surface have been well documented in both sexes and many races. Those variant patterns of talar articulating facets have been postulated that why the individual gate or other habit influencing the talocalcaneal joint are different from each other including genetic ally variant reasons (Sharada et al., 2012; Leonard, 1974).

In clinical treatments, the incidence or knowledge of the variant patterns of talar articular facets in different races has been considered to be essential information before surgical procedure or the internal and external fixation in various diseases of the foot such as talocalcaneal arthritis and coalition, flatfoot, fractures of intraarticulation, congenital or accidental dysmorphology, and valgus deformities (Uygur et al., 2009; Madhavi et al., 2008). Previously, the patterns of the facets of superior articular surface have been investigated in many populations such as Europeans (Bunning \& Barnett, 1963, 1965), Veddahs (Bunning \& Barnett, 1963, 1965), Nigerians (Bunning \& Barnett, 1963, 1965), Indians (Padmanabhan, 1986; Gupta et al., 1977; Bunning \& Barnett, 1963, 1965), Egyptians (el-Eishi, 1974), Spanish (Forriol Campos \& Gomez Pellico, 1989), Turkish (Uygur et al.), and South and North-East Indians (Sharada et al., 2012; Anjaneyulu et al., 2014). Currently, there is no systemic report about the types of talar articular facets in Thai population. Therefore this study aimed to investigate the patterns of talar articulating facets in Thai adult dried calcanei.

\section{MATERIAL AND METHOD}

This study was carried out from 396 normal adult Isan-Thai dried calcanei of identified both sex and age that they were donated for medical study in anatomy Department, Faculty of Medicine, Khon Kaen University. The samples 
were taken from 198-complete human skeletal boxes of which 101 and 97 boxes were of males and females used for this non-metrical study. The postero-superior surface of calcanei was used for numbering of the bones (Fig. 1). Based on the number of superior articular surface present on individual calcaneal bone, all bones were classified into four types (Fig. 1). Particularly, a digital vernier caliper of 0.01 $\mathrm{mm}$ accuracy was used to measure the distance between anterior (A) and middle (M) facet to distinguish the subtype facets of Type 2. In details, each type of talar articular facet was described in Figure 1.

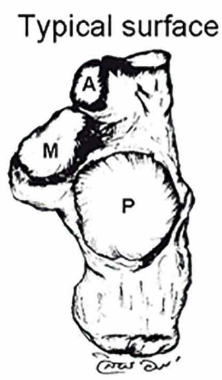

Type 1

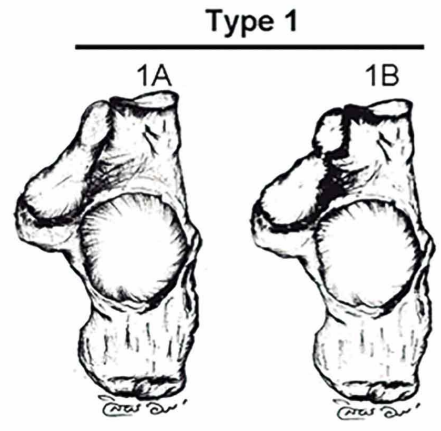

Type 2
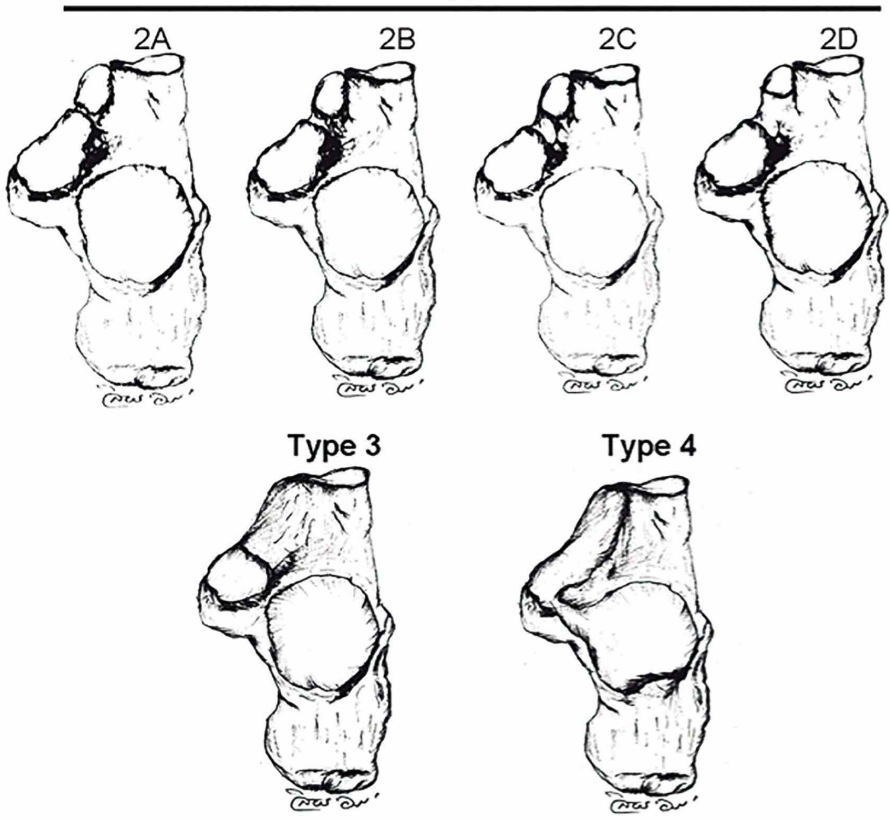

\section{RESULTS}

The age average of both sexes was approximately $66.29 \pm 14.1$ years old $($ male $=67.62 \pm 12.91$ and female= $64.96 \pm 15.29)$. The talar articular facets in Isan Thai dried calcanei investigated were classified into only 3 types (Types 1, 2, and 4) as shown in Fig. 1 and Table I and II. Type 1 had two facets $(60.86 \%)$ which Type $1 \mathrm{~A}$ (anterior non-constricted facet) and Type 1B (anterior constricted facet) were seen in $24.75 \%$ and $36.11 \%$ of cases (Fig. 1 and Table I). Type 2 had three facets $(38.64 \%)$ with differences of the anterior and middle (A-M) facet distances (Fig. 1). In details, Type 2A (A-M distance was <2 $\mathrm{mm}$ ) was found in $12.88 \%$ of cases. Type 2B (A-M distance was between $2-5 \mathrm{~mm}$ ) was seen in $14.14 \%$ of cases. Type 2C (A-M distance was $>5 \mathrm{~mm}$ with large anterior facet) was seen in $2.78 \%$ of cases. Type 2D (A-M distance was $>5 \mathrm{~mm}$ with very small anterior facet) was observed in $8.84 \%$ of cases. No type 3 (anterior facet was on the sustentaculum tali) of cases was investigated in this study (Fig. 1). In contrast, Table I showed that only 2 calcanei $(0.51 \%)$ of the cases was identified as Type 4 (presented a single fused facet) shown in Fig. 1. As compared to those of other facet types, we found that the individual percentage of Type $2 \mathrm{~A}$ of males $(15.84 \%)$ was much greater than that of females $(9.79 \%)$ while other types of females was likely to higher than that of males (Table I).

\section{DISCUSSION}

Fig. 1 Showing the illustrations of the typical and other types of facets on the superior articular surface of calcanei used as criterion for classification in this study. Upper row: individually typical superior articular surface of calcanei (A: anterior; M: middle; P: posterior) and Type 1 facet (1A: non- A$\mathrm{M}$ constricted and 1B: A-M constricted facets). Middle row: Type 2 facet (2A: A-M distance is < $2 \mathrm{~mm}$; 2B: A-M distance is between 2-5 mm; 2C: A$\mathrm{M}$ distance is $>5 \mathrm{~mm}$ with large an anterior facet; 2D: A-M distance is $>5$ $\mathrm{mm}$ with a small anterior facet) Lower row: Type 3 facet (present only two facets by the anterior one is restricted to the sustentacular tali) and Type 4 one facet (single fused facet).
In Thai population especially Isan (Northeastern) region, the largest area of Thailand, there are the richest donation of human body and skeleton for medical and paramedical study. However, the reports gained from those samples including patterns of talar articulating facets of dried calcanei are still limited as compared to the huge bone collection of our department. This study systemically showed for the first time about the types of facets on the superior articular surface of 369-dried calcanei belonging to 198 identified-Isan Thai adults. We found that the types of facets could be classified into three major types (Type1, 2, and 4) revealed in Fig. 1 and Table I. In total percentage (Table I), the type 1B was found to be the highest (35.11\%) followed by Type $1 \mathrm{~A}(24.75 \%)$, Type $2 \mathrm{~B}$ (14.14\%), Type 2A (12.88\%), Type 2C (2.78\%), and Type $4(0.51 \%)$, respectively. In the same trend, this 
Table I. Classification and percentage of talar articular facets on Isan-Thai dried cacanei.

\begin{tabular}{lcccccccc}
\hline & Type 1A & Type 1B & Type 2A & Type 2B & Type 2C & Type 2D & Type 3 & Type 4 \\
\cline { 2 - 8 } Total & 98 & 143 & 51 & 56 & 11 & 35 & 0 & 2 \\
$(\mathbf{n = 3 9 6 )}$ & $(24.75 \%)$ & $(36.11 \%)$ & $(12.88 \%)$ & $(14.14 \%)$ & $(2.78 \%)$ & $(8.84 \%)$ & $(0 \%)$ & $(0.51 \%)$ \\
Males & 45 & 71 & 32 & 26 & 8 & 18 & 0 & 2 \\
$(\mathbf{n = 2 0 2})$ & $(22.28 \%)$ & $(35.15 \%)$ & $(15.84 \%)$ & $(12.87 \%)$ & $(3.96 \%)$ & $(8.91 \%)$ & $(0 \%)$ & $(0.99 \%)$ \\
Females & 53 & 72 & 19 & 30 & 3 & 17 & 0 & 0 \\
$(\mathbf{n = 1 9 4})$ & $(27.32 \%)$ & $(37.11 \%)$ & $(9.79 \%)$ & $(15.46 \%)$ & $(1.55 \%)$ & $(8.76 \%)$ & $(0 \%)$ & $(0 \%)$ \\
\hline
\end{tabular}

Note: $*$ The percentage of Type $2 \mathrm{~A}$ of male is much greater than that of female as compared to those of other facet types.

incidence is similar to those of many races that have documented. Interestingly, the percentage of Type $2 \mathrm{~A}$ of male $(15.84 \%)$ was much greater than that of female (9.79\%) as compared to those of other facet types (Table I). As compared to fascinating investigations of Bunning \& Barnett $(1963,1965)$ investigated on samples of Europeans, Vaddahs, Nigerians, and Indians, neither this present study could not either observe Type 3 facet (Table II). In the same veins, Type 3 could not be classified in Indians (Padmanabhan), Spanish (Forriol Campos \& Gomez Pellico, 1989), Belgian (Shahabpour et al., 2011), and Turkish (Uygur et al.). In the literatures; however, it could be found the Type 3 facet only in some Indians (Gupta et al.), Egyptians (el-Eishi), South and North-East Indians (Anjaneyulu et al., 2014; Sharada et al., 2012).

Similar to the other races, the average percentage of Type 1 and Type 2 in present study was comparable or much closed to that of previous observations (Table II). Approximately, Type 1 was around 60-63\% and Type 2 was around $30-35 \%$ in all races. This information suggested that Type 1 is the most common type and Type 2 is the second common one to be observed (Table II). Interestingly, Type 4 (a single fused facet) was also found in this study
$(0.51 \%)$ which was lowest percentage compared to the rest Types. This finding trend was similar to populations of Nigerians (Bunning \& Barnett, 1963, 1965), some Indians (Gupta et al.), South Indians (Sharada et al.), and NorthEast Indians (Anjaneyulu et al.). The information or awareness about the variant patterns of facets on the talar superior articulating surface is very important for Thai clinicians in considerations before surgical procedure or the fixations in various diseases of the foot. In conclusion, the recent study has provided the first report of patterns or types of facets on the superior articular surface of Thai dried calcanei.

\section{ACKNOWLEDGEMENTS}

We would like to thank the Osteological Collection Unit, Department of Anatomy, Faculty of Medicine, Khon Kaen University, Thailand for providing the identified human dried calcanei. This study was financially supported by the invitation research grant (number: IN 58232) from Faculty of Medicine, Khon Kaen University to Assistant Professor Dr. Sitthichai Iamsaard.

Table II. Comparison between Isan-Thai race (present study) and those of other races as regards with the type and percentage of talar articular facets.

\begin{tabular}{|c|c|c|c|c|c|c|}
\hline Races & $\begin{array}{c}\text { Type } 1 \\
(\%)\end{array}$ & $\begin{array}{c}\text { Type } 2 \\
(\%)\end{array}$ & $\begin{array}{c}\text { Type } 3 \\
(\%)\end{array}$ & $\begin{array}{c}\text { Type } 4 \\
(\%)\end{array}$ & Cases & Resources \\
\hline Europeans & 67 & 32.9 & 0 & 0 & 194 & Bunning \& Barnett $(1963,1965)$ \\
\hline Veddahs & 60 & 40 & 0 & 0 & 10 & Bunning \& Barnett $(1963,1965)$ \\
\hline Nigerians & 63.4 & 37.7 & 0 & 4 & 492 & Bunning \& Barnett $(1963,1965)$ \\
\hline Indians & 78.2 & 21.7 & 0 & 0 & 78 & Bunning \& Barnett $(1963,1965)$ \\
\hline Indians & 66.8 & 25.9 & 5.2 & 1.9 & 401 & Gupta et al. (1977) \\
\hline Indians & 65 & 34.9 & 0 & 0 & 272 & Padmanabhan (1986) \\
\hline Egyptians & 49 & 40 & 11 & 0 & 200 & El-Eishi (1974) \\
\hline Spanish & 53.4 & 46.5 & 0 & 0 & 176 & Campos \& Pellico (1989) \\
\hline Turkish & 58 & 39.3 & 0 & 0 & 221 & Uygur et al. (2009) \\
\hline South Indians & 67 & 28.6 & 3 & 1.3 & 300 & Sharada et al. (2012) \\
\hline North-East Indians & 62 & 31 & 5 & 2 & 100 & Anjaneyulu et al. (2014) \\
\hline Isan Thais (This study) & 60.86 & 38.64 & 0 & 0.51 & 396 & Iamsa ard et al. (2015) \\
\hline
\end{tabular}


IAMSAARD, S.; UABUNDIT, N.; BOONRUANGSRI, P.; SAWATPANICH, T. \& HIPKAEO, W. Tipos de facetas de la superficie articular superior de calcáneos secos de tailandeses del nordeste. Int. J. Morphol., 33(4):1549-1552, 2015.

RESUMEN: Los patrones de las facetas articulares del talus deben considerarse en los procedimientos quirúrgicos o en la fijación interna y externa en varias enfermedades del pie. Variaciones en las facetas articulares del calcáneo, correspondientes a la superficie articular superior, se han reportado en muchas razas y grupos étnicos, excepto en los tailandeses. Por tanto, este estudio tuvo como objetivo investigar los patrones de presentación de las carillas articulares de calcáneos secos en Tailandases-Isan. Se estudiaron 396 huesos calcáneos secos (202 de hombres y 194 de mujeres). Los resultados mostraron que los tipos de carillas observadas se pueden clasificar en tres tipos principales (tipo 1 [60,86\%], tipo 2 [38,64\%] y Tipo 4 [0,51\%], respectivamente). Las subclasificaciones se distribuyeron en los subtipos $1 \mathrm{~A}(24,75 \%), 1 \mathrm{~B}(36,11 \%), 2 \mathrm{~A}(12,88 \%), 2 \mathrm{~B}(14,14 \%), 2 \mathrm{C}(2,78 \%), 2 \mathrm{D}(8,84 \%)$, y $4(0,51 \%)$, respectivamente. Adicionalmente, se encontró que el porcentaje del Tipo $2 \mathrm{~A}$ de hombres $(15,84 \%)$ fue mayor que en las mujeres $(9,79 \%)$ en comparación con los otros tipos. Consideramos que la incidencia de aparición de los distintos tipos de facetas constituyen una información valiosa para ortopedistas tailandeses en relación a los tratamientos a desarrollar en el área de la articulación talocalcanea.

PALABRAS CLAVE: Tipos; Facetas articulares; Talus; Calcáneo; Thailandes-Isan.

\section{REFERENCES}

Anjaneyulu, K.; Philips, C.; Tamang, B. K. \& Kumar, A. Patterns of talar articulating facets in adult human calcaneus from NorthEast India and their clinical correlation. Asian. J. Med. Sci., 5(4):89-93, 2014.

Bunning, P. S. C. \& Barnett, C. H. Variations in the talocalcaneal articulations. In: Proceedings of the Anatomical Society of Great Britain and Ireland, April 1963 and July 1963. J. Anat., 97(Pt. 4):643, 1963

Bunning, P. S. \& Barnett, C. H. A comparison of adult and foetal talocalcaneal articulations. J. Anat., 99:71-6, 1965.

Forriol Campos, F. \& Gomez Pellico, L. Talar articular facets (facies articulares talares) in human calcaneus. Acta. Anat. (Basel), 134(2):124-7, 1989

Drayer-Verhagen, F. Arthritis of the subtalar joint associated with sustentaculum tali facet configuration. J. Anat., 183(Pt. 3):6314, 1993.

el-Eishi, H. Variations in the talar articular facets in Egyptian calcaneus. Acta. Anat. (Basel), 89(1):134-8, 1974.

Gupta, S. C.; Gupta, C. D. \& Arora, A. K. Pattern of talar articular facets in Indian calcaneus. J. Anat., 124(Pt. 3):651-5, 1977.

Leonard, M. A. The inheritance of tarsal coalition and its relationship to spastic flat foot. J. Bone. Joint. Surg. Br., 56B(3):520-6, 1974.

Madhavi, C.; Madhuri, V.; George, V. M. \& Antonisamy, B. South Indian calcaneal talar facet configurations and osteoarthritic changes. Clin. Anat., 21(6):581-6, 2008.

Padmanabhan, R. The talar facets of the calcaneus--an anatomical note. Anat. Anz., 161(5):389-92, 1986.
Shahabpour, M.; Devillé, A.; Van Roy, P.; Vaes, P.; De Mey, J. \& De Maeseneer, M. Magnetic resonance imaging of anatomical variants of the subtalar joint. Surg. Radiol. Anat., 33(7):62330, 2011.

Sharada, R.; Sneha, K.; Gupta, C.; Pai, S. R. \& Rairam, G. B. Nonmetrical study of the pattern of talar articular facets in south Indian dry calcaneus. Surg. Radiol. Anat., 34(6):487-91, 2012.

Uygur, M.; Atamaz, F.; Celik, S. \& Pinar, Y. The types of talar articular facets and morphometric measurements of the human calcaneus bone on Turkish race. Arch. Orthop. Trauma Surg., 129(7):909-14, 2009.

Correspondence to:

Sitthichai lamsaard

Department of Anatomy

Faculty of Medicine

Khon Kaen University

Khon Kaen, 40002

THAILAND

Email: sittia@kku.ac.th

Received: 30-03-2015

Accepted: 24-09-2015 